\title{
Synthesis, Permeability and Microstructure of the Optimal Nickel-Zinc Ferrites by Sol-Gel Route
}

\section{S. ZAHI}

Faculty of Engineering and Technology, Multimedia University, Melaka, Malaysia.

Email: souizahi@yahoo.co.uk, souilah.zahi@mmu.edu.my

Received July $22^{\text {nd }}, 2009$; revised September $15^{\text {th }}, 2009$; accepted September $20^{\text {th }}, 2009$.

\begin{abstract}
The optimum ferrite can be obtained through free-microstructural defects where such defects are always encountered in the conventional ferrites often caused by chemical inhomogeneity. In this study, Ni-Zn ferrite was synthesized and fabricated by means of a sol-gel route. Thermal gravimetric analysis (TGA) was used to study the thermal transformation of the ferrite in air. Parts of the sol-gel powder heated at elevated temperatures were characterized by X-ray diffraction (XRD) method and Scanning Electron Microscopy (SEM) to reveal the crystallized single-phase and the structure of the obtained ferrite. Fourier transform infrared spectroscopy (FT-IR) was assisted to investigate the structure. The microstructures of the toroidal cores were obtained at two different sintering temperatures and compared with those obtained via the classic method. In addition to that, the magnetic properties were measured. The initial magnetic permeability was found to increase with the increasing of the frequency as a result of the domain wall motions and the corresponding loss was small. Therefore, a well defined polycrystalline microstructure ferrite via an easier preparation methodology as compared to the classic method is obtained.
\end{abstract}

Keywords: Ni-Zn Ferrite, RLF, Eddy Current, Sintering, Initial Permeability, Microstructure

\section{Introduction}

Nickel-zinc ferrites are the most important soft ferrites whereby the high permeability and low power loss have become the most principal requirements for the electronic devices. However, the metal oxides used in the classical ceramic process, the conventional process, produce deterioration in the final product and its properties as well as the increased handling difficulties in both the preparation and end up usages. Some of these deteriorations include the shrinkage of the materials, variations in the composition and poor homogeneity in both the chemical and crystalline structures, which mainly influence the electrical and magnetic properties [1]. Hence, the challenge is to produce the optimum soft ferrite by making changes in both the metal oxides and manufacturing process.

The sol-gel chemical methods have given numerous advantages in terms of the properties and simplicity of the technique. The attractively sol-gel favors could be represented in the ability to overcome the most drawbacks resulted from the conventional process as well as the ability to produce the nano-sized ferrite particles. The investigations on the nano-crystalline ferrite particles containing nickel and zinc using the sol-gel methods have been given much attention [2-4]. However, the principle requirements of the ferrites have been less reported. Some advantages identified in this study are the homogenous microstructure indicating the ability to better control the electro-magnetic properties as well as the shorter period and temperature of the heat treatments which decrease the variations in the composition and the impurities produced during the preparation. The sol-gel route is relatively a new technique that uses organic compounds to produce ferrite cores, which at the moment imposes a high cost in its chosen starting materials.

The ferrite which contains nickel and zinc was found to form homogenously at lower temperatures and given well controlled properties [5]. In the present paper, an extensive study on the synthesis and measurements of the initial magnetic permeability $\left(\mu_{1}\right) /$ relative loss factor (RLF) were made on toroidal ferrite cores at lower and higher temperatures. The microstructural analyses were reported on the Ni-Zn ferrites prepared via both the sol-gel route at lower and higher temperatures and the classic ceramic process.

\section{Experimental Procedures}

\subsection{Synthesis}

The starting materials, $\mathrm{Ni}\left(\mathrm{CH}_{3} \mathrm{COO}\right)_{2}, \mathrm{Zn}\left(\mathrm{CH}_{3} \mathrm{COO}\right)_{2}$ and 
$\mathrm{Fe}\left(\mathrm{CH}_{3} \mathrm{COO}\right)_{3}$ were weighed to form the spinel single-phase $\mathrm{Ni}_{0.3} \mathrm{Zn}_{0.7} \mathrm{Fe}_{2} \mathrm{O}_{4}$. These were dissolved for few hours in a small amount of acetic acid, about 5-20 ml, and adding a small amount of water facilitated their dissolutions. The clear solutions were then mixed together and stirred, while the temperature of the solution was raised from the room temperature $\left(30{ }^{\circ} \mathrm{C}\right)$ up to $70{ }^{\circ} \mathrm{C}$ and kept for a few hours. When the solution became viscous, the gel was formed and later taken out and dried at $115{ }^{\circ} \mathrm{C}$ overnight.

Parts of the dried gel were first calcined at different temperatures ranging from 600 to $1000{ }^{\circ} \mathrm{C}$ and subjected to the XRD analysis in order to reveal the crystallization of the ferrite. The dried powder was then preheated at the temperature of $600{ }^{\circ} \mathrm{C}$ maintained for 4 hours in air. The preheated powder was afterwards mixed with polyvinyl alcohol (PVA), dried between 1 and 2 wt. \%, crushed and sieved to $75-\mu \mathrm{m}$ finish. In order to make one toroid with the thickness of $4 \mathrm{~mm}$, the outer diameter of $20 \mathrm{~mm}$ and inner diameter of $12 \mathrm{~mm}, 3.75 \mathrm{~g}$ of the sieved powder was blended with $0.3 \mathrm{wt}$ \% of zinc stearate. The granulated powder was subsequently molded and pressed at the pressure of $220 \mathrm{MPa}$. The toroidal shapes were finally sintered at the different temperatures of 1200 and $1400{ }^{\circ} \mathrm{C}$ for 4 hours in air. The toroidal cores of the same composition made by the classic ceramic method were prepared to take the Scanning Electron Microscopic (SEM) images.

\subsection{Characterization}

The gel was thermally analyzed by different analytical technique (TG) in order to characterize the process produced by the heating treatment: A $6 \mathrm{mg}$ sample weight was heated in the Shimadzu TGA-500 up to $900{ }^{\circ} \mathrm{C}$ in the atmosphere air under the heating rate of $10{ }^{\circ} \mathrm{C} / \mathrm{min}$. The phase was analyzed by the XRD using $\mathrm{Cu} \mathrm{K}_{\alpha}$ radiation on a D8 Advance-Bruker diffractometer. Fourier transform infrared spectroscopic (FT-IR) analyses obtained in nickelzinc ferrite synthesis were carried out using Perkin Elmer GX Spectrometer. The photomicgraphs of the calcined samples were obtained by the Scanning Electron Microscope (JEOL JSM-6400). Both the initial permeability $\left(\mu_{1}\right)$ and loss factor (RLF) were calculated by substituting respectively the corresponding inductance $\mathrm{L}_{\mathrm{p}}$ and $\mathrm{Q}$ factor values which were measured on the sintered toroids wound with 10 turns of $340 \mathrm{~mm}$ long red copper wire, the ends of which scratched using the SiC papers and coated with Tin and finally connected to the HP network spectrum analyzer model $4195 \mathrm{~A}$ in the frequency range 10-500 $\mathrm{MHz}$ on the toroidal ferrite to their resonance frequency. The photomicrographs of the sol-gel and 10-h conventional sintered shapes were obtained on thin samples with the help of the SEM and the grain sizes were measured by the linear intercept method.

\section{Results and Discussions}

The thermo gravimetric analysis (TGA) curve recorded

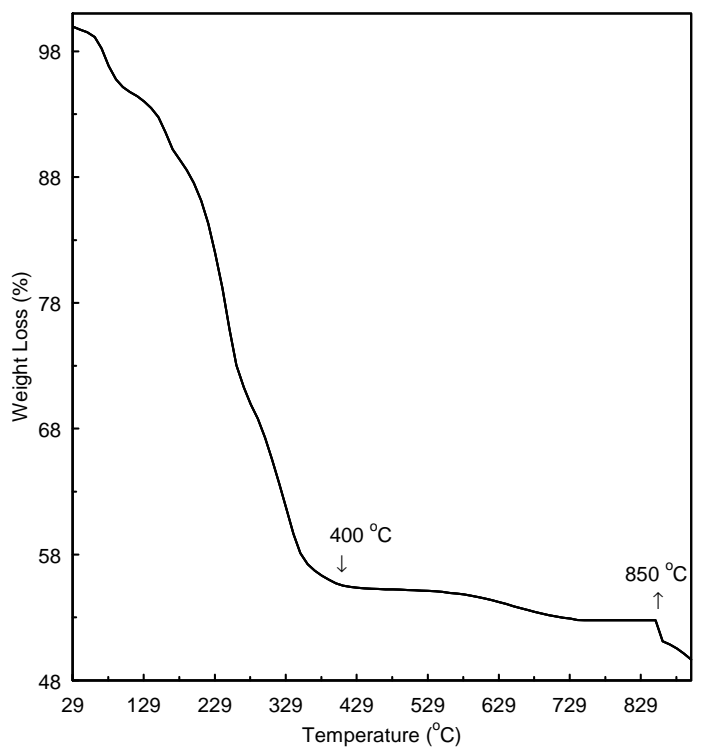

Figure 1. TG curve of the dried gel Ni-Zn ferrite powder

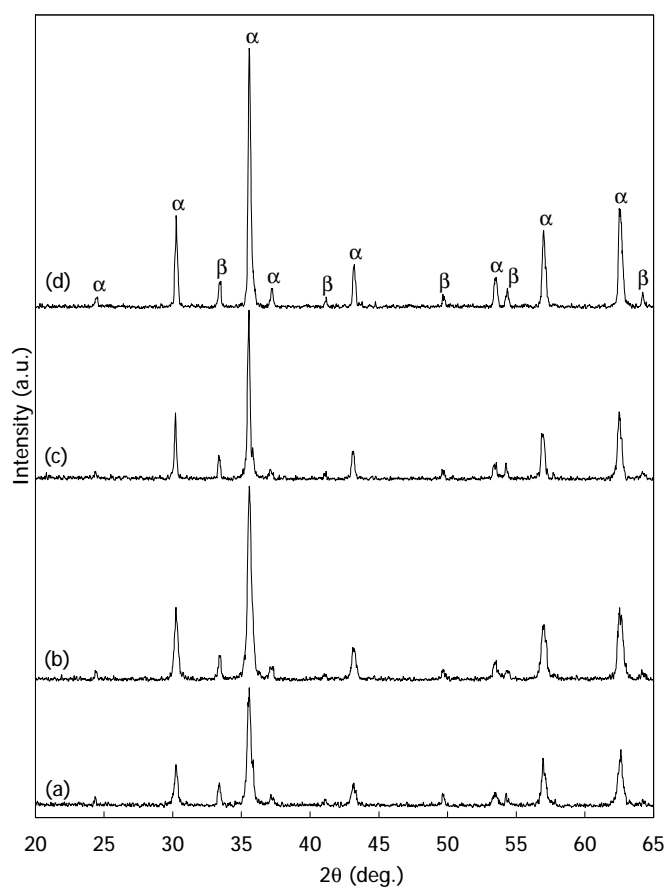

Figure 2. The crystalline phase of Ni-Zn ferrite ( $\alpha$ : nickelzinc ferrite; $\beta$ : iron oxide) at different heating temperatures: (a) $600{ }^{\circ} \mathrm{C}$, (b) $700{ }^{\circ} \mathrm{C}$, (c) $800{ }^{\circ} \mathrm{C}$, and (d) $900{ }^{\circ} \mathrm{C}$ for $4 \mathrm{~h}$ in air

while heating the dried gel in the air is shown in Figure 1. The thermal transformation can be observed in three stages. The first stage below $400{ }^{\circ} \mathrm{C}$ was attributed to the evaporation of water and the acetate complex decomposition. The mass losses connected with carboxylate ions and $\mathrm{O}-\mathrm{H}$ hydroxyl ions lied in the range of 400 to $850{ }^{\circ} \mathrm{C}$. The weight of the as-dried Nickel-zinc ferrite considerably decreased above the temperature of $600{ }^{\circ} \mathrm{C}$ which was 


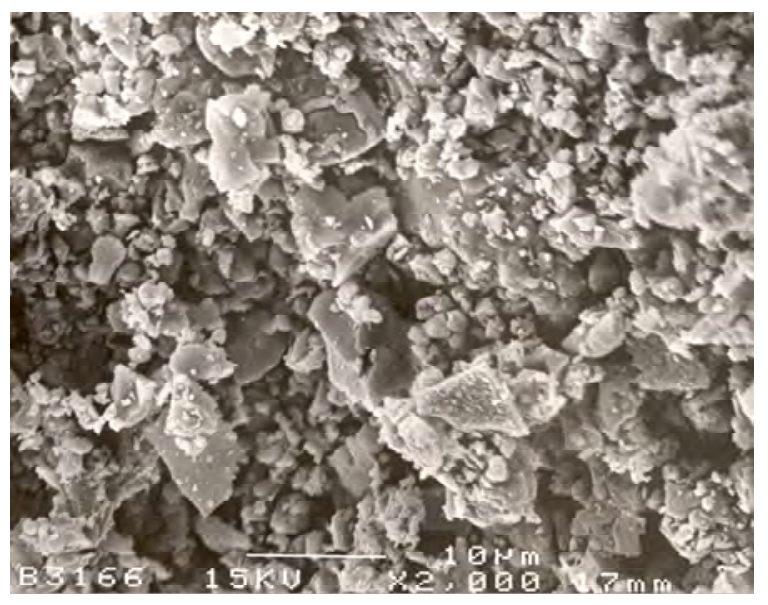

(a)

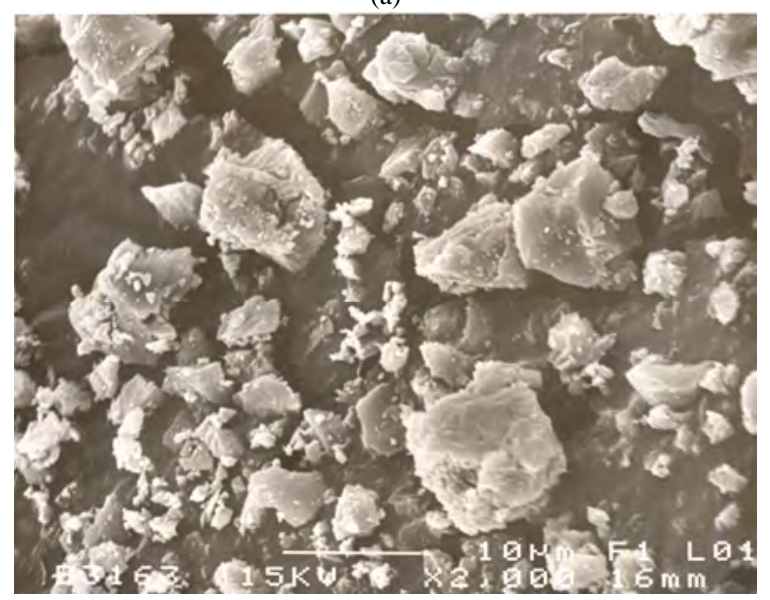

(b)

Figure 3. Micrographs of Nickel-zinc ferrite calcined at $500{ }^{\circ} \mathrm{C}$

in accordance with the reported results [6]. The sharp decrease above $850{ }^{\circ} \mathrm{C}$ indicated the last residual effect.

The XRD spectra of the powder heated at different temperature ranges for $4 \mathrm{~h}$ in air are given in Figure 2. In addition, the diffraction patterns of the powder preheated at $600{ }^{\circ} \mathrm{C}$ for $4 \mathrm{~h}$ are also presented in Figure 2. The diffraction signatures corresponding to the single-phase Nickel-zinc ferrite ( $\alpha$-phase) were detected, indicating the formation of Nickel-zinc ferrite. However, the XRD patterns corresponding to iron oxide $\mathrm{Fe}_{2} \mathrm{O}_{3}$ ( $\beta$-phase) were also detected. The ferrite was a solid solution of $\mathrm{Ni}$ and $\mathrm{Zn}$ metals containing ferric $\mathrm{Fe}^{3+}$ as the main element. Thus, the appearance of the secondary phase $\mathrm{Fe}_{2} \mathrm{O}_{3}$ meant there was more than 50 mole percent of the normal $\mathrm{Fe}_{2} \mathrm{O}_{3}$ content of the formula of spinel ferrite. On the other hand, the extra iron was to form $\mathrm{Fe}^{2+}$ ions in order to control the magnetic properties. The formation of $\mathrm{Fe}_{2} \mathrm{O}_{3}$ might also be attributed to the insufficient energy needed to attach all $\mathrm{Ni}$ and $\mathrm{Zn}$ ions with iron oxide to determine the crystal structure, as in this preheating stage the ferrite was usually partially formed where an initial and uniform aggregate of the crystallites related to the formation of Nickel-zinc ferrites occurred as previously demonstrated [5]. Moreover, the major changes observed were the increment in the intensity of the ferrite samples by more than 3 times as the heating temperature was increased. The increase in the intensity means that either the contents of the phases were increased or the concentration of the atoms in alloy was higher. Thus, the reaction was composed with the constituents of the ferrite phase.

The purpose of preheating was also to decompose the carbonates or carboxylate ions which formed from the acetate complex or O-H hydroxyl ions, thus, to start forming the ferrite lattice. Figure 3 a represents the SEM micrographs of the Ni-Zn ferrite powders calcined at 500 ${ }^{\circ} \mathrm{C}$ for $4 \mathrm{~h}$. The powder was an aggregation of particles ranging in size from less than 1 micrometer to $10 \mathrm{mi}-$ crometers. The particles were observed as uniform grains (Figure 3b) confirming the crystalline structure of Nickel-zinc ferrite which were detected by the XRD profile. The formation of $\mathrm{Fe}_{2} \mathrm{O}_{3}$ was chemically favored during the heating, whereas, the final reaction was completed during the sintering where the pores between the particles were removed combined with growth, and strong bonds between the adjacent particles were formed.

The FTIR spectra are shown in Figure 4 which helps in confirming the formation of the spinel structure in the Nickel-zinc samples. Several absorption bands were recorded in a decreasing number as the calcined temperature increased from 200 to $800{ }^{\circ} \mathrm{C}$. At the temperature of $800{ }^{\circ} \mathrm{C}$, there were two considerable bands appeared at $560\left(v_{1}\right)$ and $2350 \mathrm{~cm}^{-1}\left(v_{4}\right)$ which were assigned to the metal ion-oxygen complexes in the tetrahedral sites$\mathrm{M}_{\text {tetra }} \leftrightarrow \mathrm{O}^{-}$and traces of adsorbed or atmospheric $\mathrm{CO}_{2}$, respectively. The light band at1640 $\left(v_{3}\right)$ could be attributed to the adsorbed water or humidity [7]. On the other hand, the insensitive broadband $\left(v_{6}\right)$, around $3400 \mathrm{~cm}^{-1}$, due to $\mathrm{O} \leftrightarrow \mathrm{H}$ was not observed at the temperature of $800{ }^{\circ} \mathrm{C}$ indicating the decomposition of the carboxylate ions.

The initial permeability $\left(\mu_{1}\right)$ as a function of frequency for both the ferrites sintered at $1200{ }^{\circ} \mathrm{C}$ and $1400{ }^{\circ} \mathrm{C}$ is shown in Figure 5. The frequency band was determined up to the value below the resonance frequency. It is evident that both curves have the same trend but the initial permeability values obtained at higher temperatures are higher than the ones at the lower temperatures. The change in the initial permeability $\left(\mu_{1}\right)$, or the change in the magnetic flux density (B) represents magnetization by displacing the domain wall which is a boundary between two adjacent domains. Each grain or crystallite in this polycrystalline ferrite contained a number of domains, each differing from its neighbor only in terms of the direction of magnetization. The magnetic field $(\mathrm{H})$ for the initial permeability increased the magnetization through the reversible motion of the walls. The initial permeability increased with the increasing of frequency 

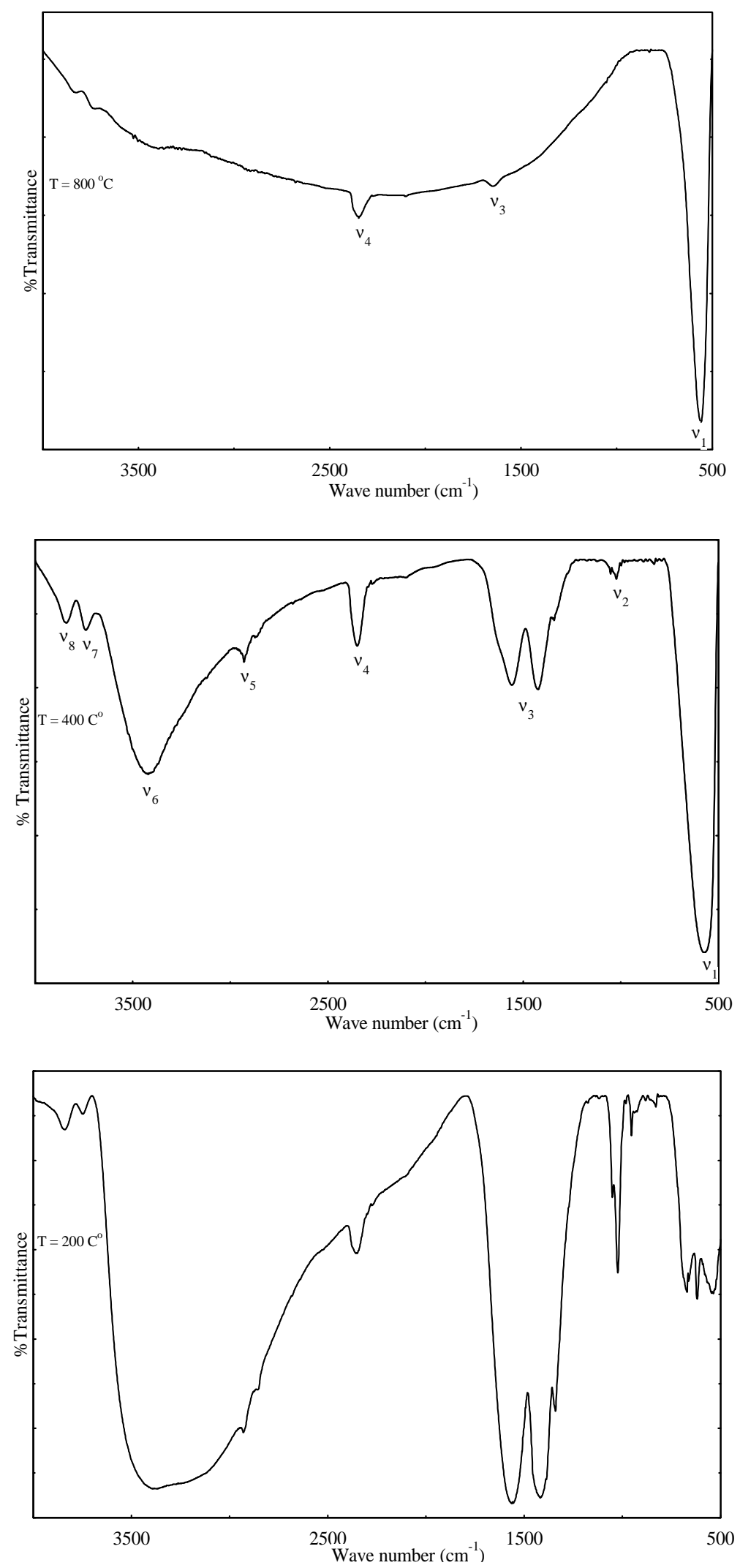

Figure 4. FTIR spectra of Nickel-zinc ferrite at the calcined temperatures of 200,400 , and $800{ }^{\circ} \mathrm{C}$ from bottom to top respectively 


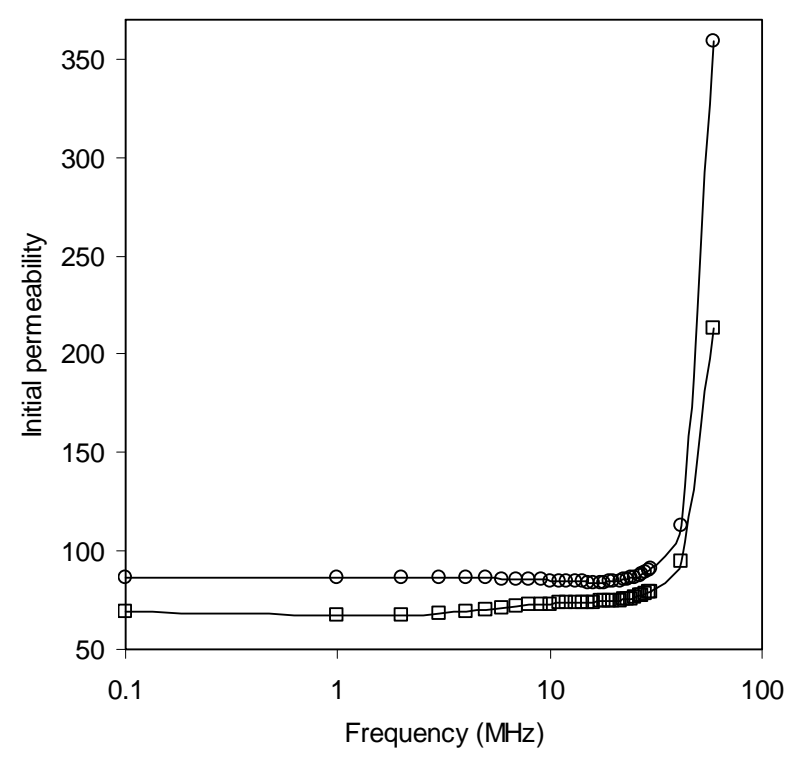

Figure 5. The initial permeability $\mu_{1}$, versus frequency: $\square$, sintered at $1200{ }^{\circ} \mathrm{C} ; \circ$, sintered at $1400{ }^{\circ} \mathrm{C}$

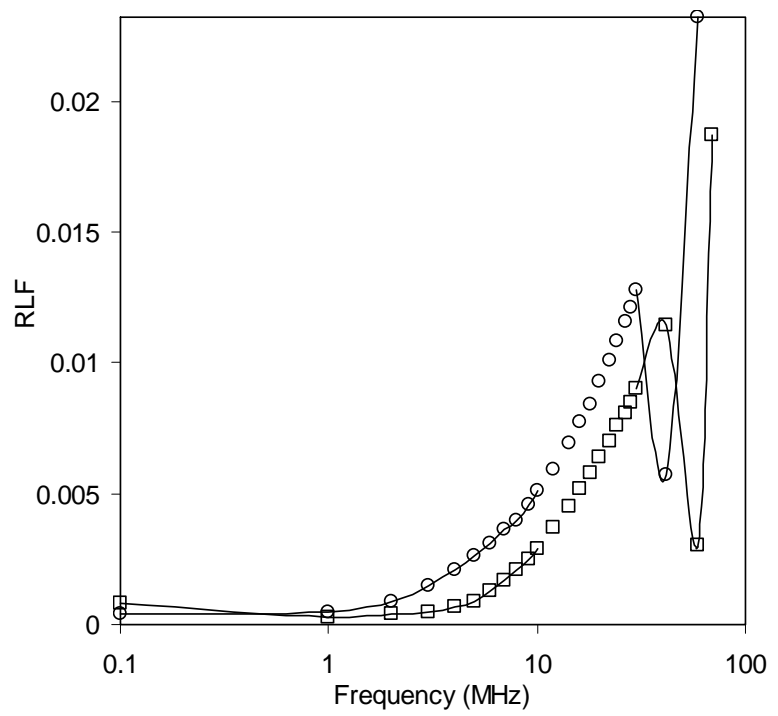

Figure 6. RLF losses versus frequency: $\square$, sintered at 1200 ${ }^{\circ} \mathrm{C}$; $\circ$, sintered at $1400{ }^{\circ} \mathrm{C}$

as a result of the increase in the size of domains owing to the fact that magnetization was projected along the same direction of the magnetic field. The increase in the magnetization was also due to the moment rotation inside the domains, which was against the anisotropy field.

The high initial magnetic permeability $\mu_{1}$ is determined by the low magnetic anisotropy $\mathrm{K}_{1}$ and the high saturation of the magnetization $\mathrm{B}_{\mathrm{s}}\left(\right.$ or $\left.\mathrm{M}_{\mathrm{s}}\right)$. Both the magnetic anisotropy and magnetostriction of the ferrites with the same composition are unchangeable at the room temperature, thus, a major contribution to $\mu_{\imath}$ is from the domain wall movements. Therefore, the increased initial permeability values at the higher temperature were due to the significant change in the domain wall motions. Ahmed [8] reported that the high permeability was attributed to the domain wall contribution, which was controlled by the increased grain size induced by higher post-sintering density. Therefore, the high initial permeability could also be controlled through the microstructure. The relationship between the grain size and initial permeability is generally linear when the grain growth is normal. Both the density and the grain size of the ferrites increased when the sintering temperature increased as many pores and open crystal structures had became closed. As a result, fewer grain boundaries and larger grains led to the higher initial permeability.

The RLF, the energy losses, versus frequency is displayed in Figure 6. The loss factor is usually analyzed into hysteresis, eddy current and residual losses. The residual loss can be considered when both the hysteresis and eddy current losses are very small. As illustrated in Figure 6, the samples prepared at $1200{ }^{\circ} \mathrm{C}$ have smaller loss and higher resonant frequency $(69 \mathrm{MHz})$. Besides, the samples prepared at $1400{ }^{\circ} \mathrm{C}$ have higher loss and lower resonant frequency $(64.7 \mathrm{MHz})$. The loss measured at $10 \mathrm{kHz}$ is 29 and $51\left(\times 10^{-4}\right)$ for the samples at the lower and higher temperatures, respectively. The hysteresis loss which gives rise to a loss tangent proportional to the peak value of the flux density $\left(\tan \delta_{\mathrm{h}} \propto \hat{B}\right)$ decreases with the saturation magnetization $\mathbf{M}_{\mathrm{s}}$. Thus, when the sintering temperature increased, the domains or the wall motions were activated, i.e. increasing the magnetization and the magnetic loss. The contribution of the eddy current loss could be estimated via the grain boundary resistivity. Usually, small grains with prominent grain boundaries lead to higher resistivity, the eddy current loss of which is negligible. Therefore, the increased losses in the samples sintered at the higher temperature were mainly due to the significant eddy current as well as the energy lost as the magnetization increased.

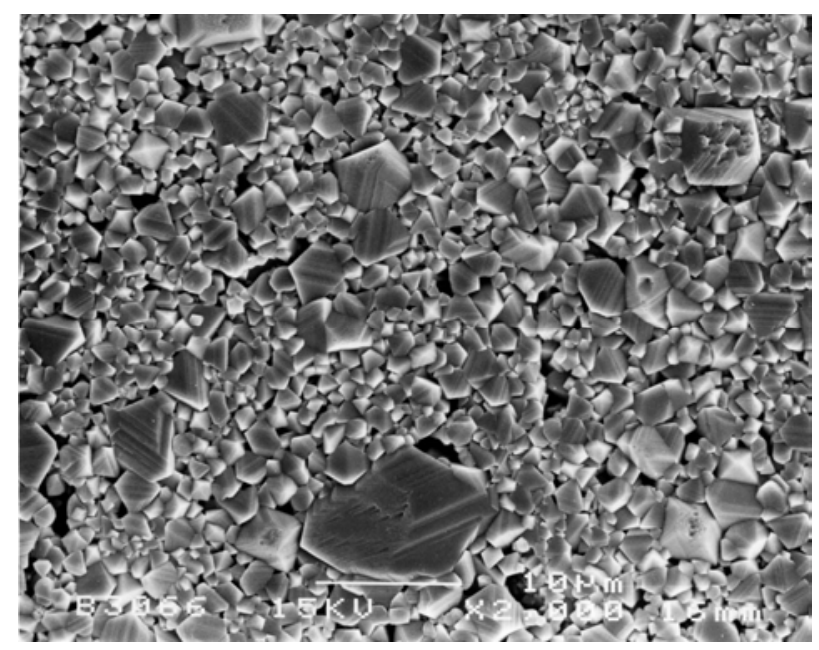

Figure 7. Micrographs of Ni-Zn ferrite sinterd at $1200{ }^{\circ} \mathrm{C}$ 


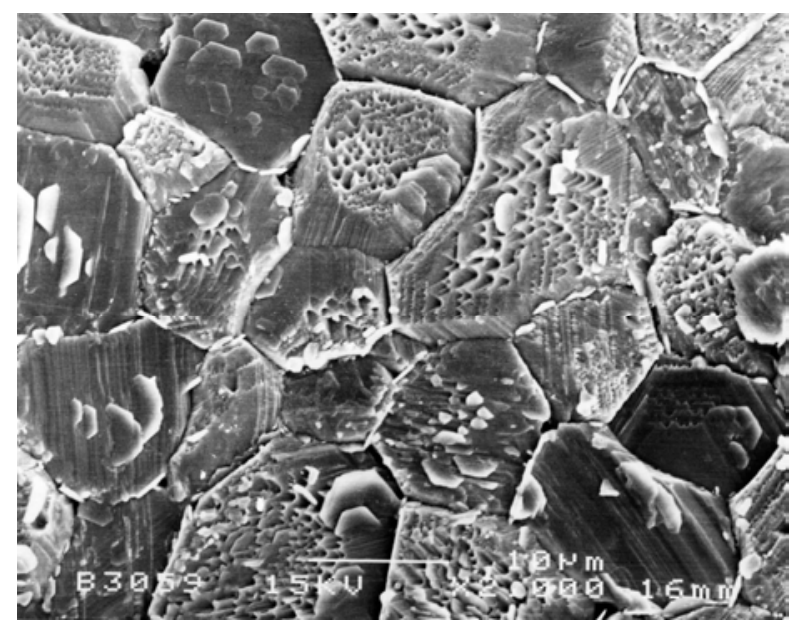

Figure 8. Micrographs of $\mathrm{Ni}-\mathrm{Zn}$ ferrite sinterd at $1400^{\circ} \mathrm{C}$

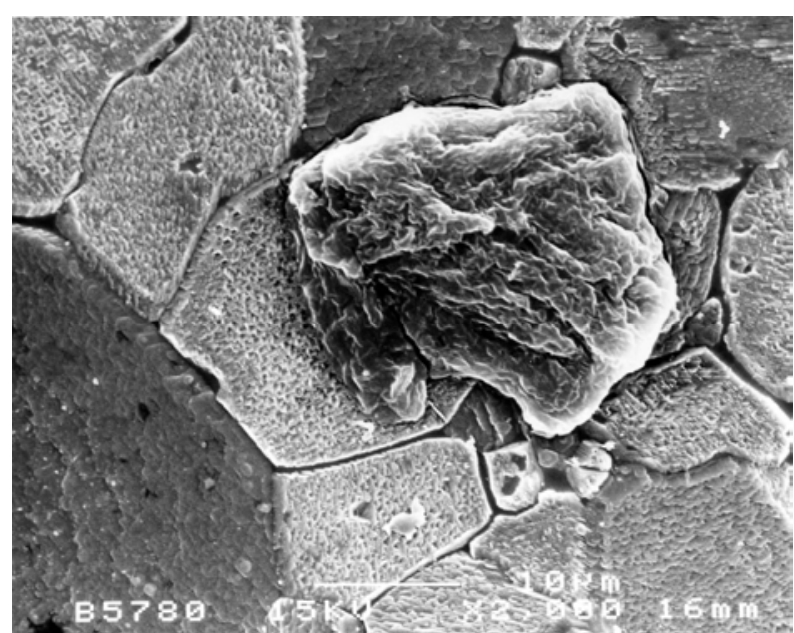

Figure 9. Micrographs of the conventional Ni-Zn ferrite showing segregation

The microstructures of the Ni-Zn ferrites sintered at the lower and higher temperatures are given in Figures 7 and 8 , respectively. Both the ferrites showed the grains and the grain boundaries. The grain size measured at $1200{ }^{\circ} \mathrm{C}$ was $1.6 \mu \mathrm{m}$ indicating smaller grains, while at $1400{ }^{\circ} \mathrm{C}$ was $18.8 \mu \mathrm{m}$ indicating bigger grains. The microstructure of the same composition which was 10-h conventionally obtained at $1300^{\circ} \mathrm{C}$ is shown in Figure 9.

There were many grains presented (Figure 7) and a large number of grain boundary regions or small contact between the adjacent grains. These small grains are to contain a small number of domains but many grains normally contain many domains. Hence, the grain boundaries acted as the impediment to the domain wall movement, which limited the permeability. The undesirable imperfections that could impede the domain wall motion such as pores, impurities, second phases and other defects such as duplex structure were not signed on both the X-ray signatures and microstructure.

The SEM of the ferrite sintered at the higher tempera- tures (Figure 8) showed larger grains with intragranular pores (i.e., on grains). There were fewer grains and higher adjacent contacts which led to the higher permeability. The high temperature caused a rapid grain grow in some grains; they are bigger than the other narrow grains. This led to many intragranular pores which possibly contributed in decreasing permeability and increasing the losses. On the other hand, such pores were not seen in the ferrite sintered at the lower temperatures, except for the intergranular pores (i.e., between grains) which were observed and could be eliminated by increasing the presintering temperature. Therefore, these facts suggest a very high homogeneity as the microstructure is also similar in the final composition.

In the conventional ferrite, the impurities presented in the raw materials would be present in the finished ferrite which put a considerable burden to produce a good quality ferrite. Conventionally, the duplex structure (Figure 9) which has some very large grains in the matrix of fine grains is mostly due to the segregation of a particular impurity such as $\mathrm{SiO}_{2}$. Goldman [9] proved that the segregations could affect the surrounding area, trap pores, and limit permeability by pinning domain walls and increases losses. At still higher concentration, the impurity $\mathrm{SiO}_{2}$ could be reacted with any additives such as $\mathrm{CaO}$, possibly through the formation of $\mathrm{CaSiO}_{3}$, which led to the uncontrolled and undesired electro-magnetic properties.

\section{Conclusions}

The sol-gel method is convenient for the fabrication of $\mathrm{Ni}-\mathrm{Zn}$ ferrite optimum cores. The compound $\mathrm{Ni}_{0.3} \mathrm{Zn}_{0.7}$ ferrite has been studied using TGA, XRD, SEM, and FTIR analyses. In addition, the electromagnetic and microstructural properties of the cores for electronic applications have been investigated. The analysis has led to the conclusions as follows: 1) the crystallized single-phase ferrite was formed at low cost sol gel preparation; 2) the extra $\mathrm{Fe}^{+3}$ ions in the normal $\mathrm{Fe}_{2} \mathrm{O}_{3}$ content of the formula of spinel ferrite led to the formation of secondary phase for the control of the magnetic properties; 3) the high initial magnetic permeability, small magnetic and eddy current losses were obtained at lower temperatures; 4) higher initial magnetic permeability and relatively small magnetic and eddy current losses were further obtained through controlling the grain size; 5) fine-grained microstructures obtained through easier preparation methodology as compared to the conventional ferrite was realized, mainly by reducing time and temperature of the heat treatments and eliminating the mixing and milling steps; and 6) the technique seemed to be further simplified through choosing new starting materials.

\section{Acknowledgements}

The authors wish to thank Professor A.R. Daud from National University of Malaysia for his help to carry out the FTIR measurements, and Associate Professor M. Hashim from the University Putra of Malaysia for his comments at a stage of the preparation of the manuscript. 


\section{REFERENCES}

[1] E. E. Sileo, R. Rotelo, and S. E. Jacobo, "Nickel-zinc ferrites prepared by the citrate precursor method," Physica B: Condensed Matter, Vol. 320, pp. 257-260, 2002.

[2] H. E. Zhang, B. F. Zhang, G. F. Wang, X. H. Dong, and Y. Gao, "The structure and magnetic properties of $\mathrm{Zn}_{1-x} \mathrm{Ni}$ ${ }_{x} \mathrm{Fe}_{2} \mathrm{O}_{4}$ ferrite nanoparticles prepared by sol-gel autocombustion," Journal of Magnetism and Magnetic Materials, Vol. 312, pp. 126-130, 2007.

[3] J. Azadmanjiri, "Structural and electromagnetic properties of Ni-Zn ferrites prepared by sol-gel combustion method," Materials Chemistry and Physics, Vol. 109, pp. 109-112, 2008.

[4] M. Yu, J. Liu, and S. Li, "Fabrication and characterization of highly ordered $\mathrm{Ni}_{0.5} \mathrm{Zn}_{0.5} \mathrm{Fe}_{2} \mathrm{O}_{4}$ nanowire/tube arrays by sol-gel template method," Journal of University of Science and Technology Beijing, Vol. 14, pp. 469-472, 2007.
[5] S. Zahi, M. Hashim, and A. R. Daud, "Synthesis, magnetic properties and microstructure of $\mathrm{Ni}-\mathrm{Zn}$ ferrite by sol-gel technique," Journal of Magnetism and Magnetic Materials, Vol. 308, pp. 177-182, 2007.

[6] Y. P. Fu, C-H. Lin, and C-W. Liu, "Preparation and magnetic properties of $\mathrm{Ni}_{0.25} \mathrm{Cu}_{0.25} \mathrm{Zn}_{0.5}$ ferrite from microwave-induced combustion," Journal of Magnetism and Magnetic Materials, Vol. 283, pp. 59-64, 2004.

[7] M. Jalaly, M. H. Enayati, F. Karimzadeh, and P. Kameli, "Mechanosynthesis of nanostructured magnetic Ni-Zn ferrite," Powder Technology, Vol. 193, pp. 150-153, 2009.

[8] T. T. Ahmed, I. Z. Rahman, and M. A. Rahman, "Study on the properties of the copper substituted Ni-Zn ferrites," Journal of Materials Processing Technology, Vol. 153154, pp. 797-80, 2004.

[9] A. Goldman, "Modern ferrite technology," Van Nostrand Reinhold, New York, pp. 121-12, 1990. 